Animal Genetics

Volume 38 Issue 4 Page 340-349, August 2007

http://dx.doi.org/ 10.1111/j.1365-2052.2007.01611.x

(c) 2007 Blackwell Publishing, Inc.
Archimer, archive institutionnelle de l'Ifremer http://www.ifremer.fr/docelec/

\title{
AFLP-based genetic linkage maps of the blue mussel (Mytilus edulis)
}

\author{
D. Lallias ${ }^{1,2}$, S. Lapègue ${ }^{1}$, C. Hecquet ${ }^{1}$, P. Boudry ${ }^{1}$ and A.R. Beaumont ${ }^{2}$
}

1. Ifremer, Laboratoire Génétique et Pathologie, Ronce-les-bains, 17390 La Tremblade, France

2. School of Ocean Sciences, College of Natural Sciences, University of Wales, Bangor, Menai Bridge, Gwynedd, LL59 5AB, United Kingdom

Corresponding author:

Andy R. Beaumont

School of Ocean Sciences

College of Natural Sciences

University of Wales, Bangor

Menai Bridge

Gwynedd

LL59 5AB

United Kingdom

Tel. (44) (0) 1248382849

Fax. (44) (0) 1248716367

Email:a.r.beaumont@bangor.ac.uk

\begin{abstract}
:
We report the construction of the first genetic linkage map in the blue mussel, Mytilus edulis. AFLP markers were used in a 86 full-sib progeny from a controlled pair mating, applying a double pseudotest cross strategy. Thirty six primer pairs generated 2354 peaks, of which 791 (33.6\%) were polymorphic in the mapping family. Among those, 341 segregated through the female parent, 296 through the male parent (type 1:1) and 154 through both parents (type 3:1). Chi-square goodness of fit tests revealed that $71 \%$ and $73 \%$ of type 1:1 and 3:1 markers respectively segregated according to Mendelian inheritance. Sex-specific linkage maps were built with MapMaker 3.0 software. The female framework map consisted of 121 markers ordered into 14 linkage groups, spanning $862.8 \mathrm{cM}$, with an average marker spacing of $8.0 \mathrm{cM}$. The male framework map consisted of 116 markers ordered into 14 linkage groups, spanning $825.2 \mathrm{cM}$, with an average marker spacing of $8.09 \mathrm{cM}$. Genome coverage was estimated to be $76.7 \%$ and $75.9 \%$ for the female and male framework maps respectively, rising to 85.8 (female) and $86.2 \%$ (male) when associated markers were included. Twelve probable homologous linkage group pairs were identified and a consensus map was built for 9 of these homologous pairs based on multiple and parallel linkages of 3:1 markers, spanning $816 \mathrm{cM}$, with JoinMap 4.0 software.
\end{abstract}

Keywords genetic linkage map, AFLP, blue mussel, Mytilus edulis. 


\section{Introduction}

The blue mussel Mytilus edulis is a bivalve mollusc of major commercial importance with a worldwide production of around $1.5 \mathrm{mt}_{\mathrm{yr}} \mathrm{r}^{-1}$ (FAO, 2002). Additionally, mussels are among the best studied species of the littoral and sublittoral communities and have been the focus of research into genetics, biochemistry, physiology and ecology (Gosling 1992). Despite their economical importance, most bivalves - including mussels - have not been domesticated like agricultural animals or crops and their production is mainly based on collection of natural spat (i.e. juveniles). However, selective breeding programs have been initiated in some bivalve species (e.g. Pacific oyster: http://hmsc.oregonstate.edu/projects/mbp/, green shell mussel: http://www.cawthron.org.nz/aquaculture/selective-breeding.html). In the blue mussel, quantitative genetic studies of traits of economical importance for growth and length (Mallet et al. 1986; Stromgren \& Nielsen 1989) suggest that significant improvement could be achieved by selective breeding. In this context, the development of genetic and genomic tools are likely to contribute to the development of selective breeding programs, and, more generally, to improve knowledge about the genome of this species of aquacultural and ecological importance. Genetic linkage maps based on polymorphic markers such as AFLPs, RAPDs and microsatellites have been generated in several aquaculture species such as salmon (Moen et al. 2004), tilapia (Kocher et al. 1998) or shrimp (Li et al. 2006). In bivalves, genetic maps have been established in the Pacific oyster Crassostrea gigas (Hubert \& Hedgecock 2004; Li \& Guo 2004), the Eastern oyster Crassostrea virginica (Yu \& Guo 2003) and the Zhikong scallop Chlamys farreri (Wang et al. 2004; Li et al. 2005; Wang et al. 2005). Such maps represent a framework which enables the identification and localisation of QTL (Quantitative Trait Locus) (e.g. Yu \& Guo 2006) with the final aim of achieving genetic improvement through marker-assisted selection (MAS) (Liu \& Cordes 2004).

Only seven microsatellites have so far been published for the blue mussel (Presa et al. 2002) and, although more than 20 allozyme markers have been developed for the mussel, their relatively low polymorphism makes them unsuitable for extensive mapping (Beaumont 1994). Therefore, AFLP markers (Vos et al. 1995) were chosen as they require no preliminary knowledge of the genome, are highly reproducible (Jones et al. 1998) and can generate relatively quickly a high number of markers dispersed across the 14 pairs of chromosomes in the mussel genome.

\section{Material and methods}

\section{Mapping family}

A full-sib mapping family was produced from two wild mussels collected from the Menai Strait, Wales, UK, since there has been no domestication of mussels and no homozygous nor selected lines are available. The methods used for gamete release, fertilisation and larval development were essentially as described

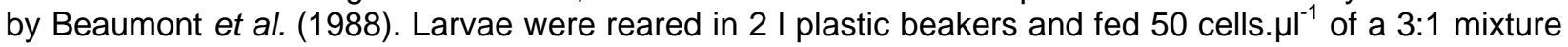
Pavlova lutheri and Rhinomonas reticulata. Filtered $(1 \mu \mathrm{m})$ and UV-light treated water was changed three times a week when food was added. Ready-to-settle larvae were held on $80 \mu \mathrm{m}$ sieves in a downwelling system (Utting \& Spencer 1991) to allow metamorphosis and spat were fed a mixture of $P$. lutheri, Chaetoceros calcitrans and Isochrysis galbana clone T-Iso. Sieve mesh sizes were increased as mussel juveniles grew in size and mussels were transferred to IFREMER, La Tremblade, France when 2 monthold for further ongrowing. Several full-sib families were produced but only one was randomly chosen for study and DNA was extracted from 86 20-month old F1 mussels.

\section{DNA extraction}

DNA was extracted from gill tissue using a chloroform extraction followed by purification with the Wizard ${ }^{\circledR}$ DNA Clean-Up System (Promega), according to Wilding et al. (2001). Quality and concentration of DNA was assessed using a spectrophotometer and by running a small sample on a $2 \%$ agarose gel. High quality extracted DNA was adjusted to a concentration of $100 \mu \mathrm{g} \cdot \mathrm{ml}^{-1}$. 


\section{AFLP analysis}

AFLP analysis was performed by using a modified version of Vos et al. (1995), following Wilding et al.'s (2001) protocol, but digestion and ligation were achieved in the same mix and incubated 16 hours at $16^{\circ} \mathrm{C}$. Electrophoresis and data collection was carried out on an ABI 3100-Avant (Applied Biosystems). Electrophoresis parameters were set at injection for $15 \mathrm{~s}$ at $15 \mathrm{kv}$, running for 25 min at $15 \mathrm{kv}$ and $60^{\circ} \mathrm{C}$, with POP4 polymer. Repeatability of the technique was checked by comparing the band pattern of four replicates obtained independently (four different DNA extractions: 2 gill, 2 muscle, four different AFLP amplifications (primer pair A1), performed on different days) on the same 20 samples of $M$. edulis. Results of this trial showed that consistent band patterns were obtained.

Thirty six AFLP primer pairs were genotyped in the mapping family (Supplemental Table S1). Two negative controls were included in each PCR reaction to detect any potential contamination. Data were analysed with GeneMapper ${ }^{\circledR}$ software version 3.7 and individuals were scored for the presence $[A]$ or absence [a] of the amplified AFLP fragment.

\section{Distortion of segregation ratios}

Two kinds of segregating AFLP markers could be detected. Type 1:1 markers where one parent was heterozygous for the band and the other homozygous for no band and the F1 progeny were expected to segregate 1:1, band: no band. Type 3:1 markers corresponded to AFLPs where both parents were heterozygous for the band and the progeny were expected to segregate $3: 1$, band: no band. A chisquared goodness of fit test for the 1:1 or 3:1 segregation ratios was applied to each locus. All distorted markers $(p<0.05)$ were excluded from further linkage analysis.

\section{Establishment of sex-specific framework linkage maps: MapMaker 3.0 software}

MapMaker 3.0 software (Lander et al. 1987) was used to build sex-specific linkage maps, based on type 1:1 segregating markers in a double pseudo-test cross ( $F 2$ backcross model, $A a=H, a a=A$ ) (Grattapaglia \& Sederoff 1994). Each dataset was duplicated and recoded to allow the detection of markers linked in repulsion phase (" $r$ " added at the end of their names; e.g. marker A1f123r was the recoded marker of marker A1f123). Linkage groups were determined with the GROUP command of MapMaker, conducted at LOD score $\geq 4.0$ and genetic distance $\leq 37.5 \mathrm{cM}$. Once linkage groups were determined, the markers were ordered by the COMPARE command for a limited number of markers $(n \leq 9)$, or otherwise by the THREE POINT and ORDER commands. After the ordering of markers within each linkage group, the RIPPLE command allowed the testing of robustness of the map obtained. Markers that presented a conflict in map position (several map positions possible, with a small difference of LOD score) were placed as associated markers. The ERROR DETECTION command (Lincoln \& Lander 1992) was on during all the analyses described above to detect eventual genotyping errors. Map distances in centiMorgans were calculated using Kosambi's mapping function (Kosambi 1944) and linkage groups were drawn with MapChart software (Voorrips 2002).

\section{Establishment of a consensus map: JoinMap 4.0 software}

Male and female maps based on 1:1 and 3:1 segregating AFLP markers and a consensus map were achieved using JoinMap 4.0 software (Van Ooijen 2006). Male and female datasets were treated independently, as a population type CP (composite). First, the two parental maps based on 1:1 and 3:1 markers were built. Then, homologous pairs of linkage groups were identified by multiple and parallel linkages of markers, i.e. several markers ordered in the same order in both parental maps. Only 3:1 markers that did not contradict the mapping order of framework markers, previously established with MapMaker, were retained for the establishment of a consensus map. Recombination rates were converted into genetic distances (in $\mathrm{cM}$ ) using Kosambi's mapping function and linkage groups were drawn with MapChart software (Voorrips 2002). 


\section{Genome length and map coverage}

Average marker spacing of the framework map was calculated by dividing the total length of the map by the number of intervals. In the same way, the average marker spacing for each linkage group was calculated by dividing the length of each linkage group by the number of intervals on that linkage group. The expected length of the genome was estimated using method 4 of Chakravarti et al. (1991), based on framework markers alone and then with framework and associated markers. Observed genome coverage estimates were determined by dividing the observed genome length (total length in $\mathrm{cM}$ of all the linkage groups) by the expected length of the genome. Two observed genome coverage estimates were computed, whether or not associated markers were taken into account.

\section{Results}

The 36 primer pairs, screened for 86 F1 progeny and their two parents, generated a total of 2354 peaks, averaging 65 peaks per pair. The average number of segregating markers (among the two parents, including both types of markers) was 791 , or 22 per primer pair, corresponding to $33.6 \%$ of polymorphic peaks. Among the 791 polymorphic markers in the mapping family, 341 were segregating through the female parent, 296 through the male parent and 154 through both parents. Chi-square analysis indicated that $243(71.3 \%)$ and $210(70.9 \%)$ of the markers segregated according to the expected 1:1 Mendelian ratio in the female and male respectively; and that $112(72.7 \%)$ markers segregated according to the expected 3:1 Mendelian ratio. Distorted markers $(p<0.05)$ were discarded from further linkage analysis.

\section{Sex-specific linkage maps}

The female framework map established with MapMaker 3.0, based on the 243 AFLP markers segregating through the female parent only, consisted of 121 markers (49.8\%). Seven markers were not linked to the framework map (2.9\%). Additionally, 115 markers were linked to the framework map with a LOD score of 4.0 but not placed accurately and were therefore considered as "associated markers". Associated markers were located beside their closest framework marker (Supplemental Table S2). Fourteen linkage groups were identified for the female map covering $862.8 \mathrm{cM}$ (Figure 1). The sizes of the linkage groups ranged from $9.5 \mathrm{cM}$ to $101.5 \mathrm{cM}$. The number of framework markers per linkage group varied from 2 to 16 , and the number of associated markers from 0 to 23. The average distance between 2 framework loci ranged from $4.09 \mathrm{cM}(\mathrm{G} 10 \mathrm{~F})$ to $19.5 \mathrm{cM}(\mathrm{G} 12 \mathrm{~F})$, with an average spacing of $8.06 \mathrm{cM}$. The maximum interval of the female map was $32.9 \mathrm{cM}$ (G2F) (Table 1). Some clusters of AFLPs could be observed, containing from 2 to 7 markers. A single linkage group could contain up to 4 clusters (e.g. G1F). The estimated genome length was $1125.3 \mathrm{cM}$. The observed coverage was therefore $76.7 \%$ for the female framework map. When associated markers were considered, the estimated genome length was $1006.0 \mathrm{cM}$ and genome coverage became $85.8 \%$ for the female map.

The male framework map established with MapMaker 3.0 was based on the 210 AFLP markers segregating through the male parent only. The resulting map consisted of 116 framework markers (55.2\%). Six markers were not linked to the framework map (2.9\%). Additionally, 88 markers were placed as associated markers (Supplemental Table S3). Fourteen linkage groups were set up for the male map covering $825.2 \mathrm{cM}$ (Figure 2). The sizes of the linkage groups ranged from $20.3 \mathrm{cM}$ to $86.5 \mathrm{cM}$. The number of framework markers per linkage group varied from 3 to 20, and the number of associated markers from 1 to 14 . The average distance between 2 framework loci ranged from $3.08 \mathrm{cM}(\mathrm{G} 13 \mathrm{M})$ to $15.4 \mathrm{cM}(\mathrm{G} 6 \mathrm{M})$, with an average spacing of $8.09 \mathrm{cM}$. The largest interval varied from $8.2 \mathrm{cM}(\mathrm{G} 13 \mathrm{M})$ to $37.6 \mathrm{cM}(\mathrm{G} 1 \mathrm{M})$ (Table 1). Some clusters of AFLPs could be observed, containing from 2 to 7 markers. A single linkage group could contain up to 6 clusters (G8M). All framework markers were mapped with a LOD score of 4.0 except marker A6f121r of G5M that was linked to this group with a LOD score of 2.79. For the male map, the estimated genome length was $1087.1 \mathrm{cM}$ and observed coverage was $75.9 \%$. Including associated markers, the estimated genome length was reduced to $957.6 \mathrm{cM}$ with genome coverage of $86.2 \%$. 


\section{Marker distribution}

There was a random distribution among linkage groups of all markers generated by the three different EcoRI primers. A contingency chi-square test for the 14-groups $\times 3$-EcoRI primers was not significant for either female or male ( $x^{2}=12.720$ or $24.604,22$ d.f., $p=0.316$ or 0.941 respectively). The female and male framework maps (Figures 1 and 2) revealed a high number of clusters, 43 on the female and 36 on the male map. Uneven distribution of markers means that gaps remain to be filled because both maps show intervals spanning more than $20 \mathrm{cM}$. The assumption of a random distribution of AFLP markers across the genome was tested using Spearman correlation coefficients and chi-square test for departure from a Poisson distribution. Spearman correlation coefficients $\left(r_{s}\right)$ between genetic length and number of markers per group were 0.481 for the male $(p>0.05)$ and 0.635 for the female $(p<0.05)$. However, when a single outlier linkage group was removed from the male dataset, the correlation became significant $(p<0.05)$. Therefore, in spite of observed clusters, AFLP markers generally tended to be randomly distributed in the linkage maps.

Observed and expected distributions of AFLPs were compared over $20 \mathrm{cM}$ intervals in female and male framework maps. A chi-square test for departure from a Poisson distribution was computed. The mean of the Poisson distribution was set up to the mean number of markers per $20 \mathrm{cM}$ interval length: 2.61 for the female and 2.8 for the male maps. No significant departure from the Poisson distribution was observed for the female $\left(x^{2}=13.22,7\right.$ d.f., $\left.p=0.067\right)$. However, this goodness-of-fit test was highly significant for the male $\left(x^{2}=28.63,7\right.$ d.f., $\left.p<0.001\right)$, mostly due to three intervals of $20 \mathrm{cM}$ containing eight markers. This confirms that clustering of AFLPs was more important in the male framework map, with the presence of a few dense clusters of markers (containing up to seven markers).

\section{Preliminary consensus map}

Twelve probable homologous linkage groups were identified and for nine of them, a consensus map was established based on at least three markers of type 3:1 exhibiting multiple and parallel linkages (Figure 3). Up to four 3:1 markers were used to build a consensus group. These consensus groups were named according to the names of the groups they derived from, e.g. consensus group G10F_G11M_comb issued from the joining of groups G10F of the female map and G11M of the male map. For three of the twelve probable homologous groups, a consensus map was difficult to construct (Figure 4). For example, the homology of groups G7F and G14M was based on a single marker (B1f123*). The homology of groups G11F and G12M was based on the parallel and multiple linkage of three markers (B4f222*, E10f66* and E10f78*) but the alignment of these two groups according to these three markers indicated that G12M could be homologous to only the terminal part of G11F, making the establishment of a consensus map difficult and potentially unreliable. Finally, the male group G6M seemed to have two potential homologes in the female map: G13F and G7Fpartial, assessed by three and two markers of type 3:1 respectively. Despite the mapping of a few 3:1 markers, no clear homologes could be identified for the male groups G3M and G10M nor for the female groups G8F and G12F.

The observed genome lengths obtained for the female, the male and the consensus maps established with MapMaker and JoinMap were very similar: 863 and $825 \mathrm{cM}$ for the female and male maps (MapMaker), 871 and $799 \mathrm{cM}$ for the female and male maps (JoinMap) and $816 \mathrm{cM}$ for the consensus map.

\section{Discussion}

In our mapping family of $M$. edulis, segregation distortion $\left(x^{2}, p<0.05\right)$ averaged $29 \%$ for the type $1: 1$ markers, and $27 \%$ for the type 3:1 markers. The observed numbers of distorted markers were 98 for the female 1:1 markers, 86 for the male 1:1 markers and 42 for the 3:1 markers, and were higher than the expected numbers by chance only $(17,15$ and 8 respectively at $\alpha=5 \%)$.

High segregation distortion could be caused by technical artefacts in genotyping such as size homoplasy (i.e. AFLP fragments showing the same size but belonging to different loci). Incomplete enzyme digestion and/or inefficient PCR represent another technical artefact, leading towards null homozygous AFLP genotypes. In our study, around 60\% of the distorted markers were deficient for homozygous null genotypes, ruling out technical artefacts as the main source of non-Mendelian 
segregation. Finally, the relatively high proportion of distorted markers (towards a homozygote deficiency) could be explained by linkage of markers with lethal or deleterious genes in recessive state that cause genotype-dependant mortalities. A high genetic load has previously been reported in bivalves (McGoldrick \& Hedgecock 1997; Bierne et al. 1998; Launey \& Hedgecock 2001) and is therefore to be the most likely hypothesis explaining our results.

To our knowledge, maps presented in our study represent the first genetic linkage maps established in the blue mussel $M$. edulis. Despite their preliminary nature, these male and female maps offer a good representation of the blue mussel genome. Firstly, both maps contain 14 linkage groups, which correspond to the haploid number of chromosome of this species (Thiriot-Quiévreux 1984). Secondly, total map length observed in this study is similar to the theoretical genetic length based on 1.01.3 crossing over per chromosome. The observed genetic length was $825.2 \mathrm{cM}$ for the male map, and $862.8 \mathrm{cM}$ for the female map. Work on the Pacific and Eastern oysters $(2 n=20)$ revealed an average number of chiasmata per chromosome of -1.1-1.2 (Guo, X., unpublished data cited in Li \& Guo 2004). Based on these data, assuming a hypothetical range of 1.0-1.3 chiasmata per chromosome for $M$. edulis, the theoretical map length should range 700 to $910 \mathrm{cM}(1.0$ or $1.3 \times 50 \mathrm{cM} \times 14$ chromosomes). The observed total genetic length for both maps in our study falls into that range. Moreover, expected genome lengths estimated in this study (957-1006 cM) were 5-36\% longer than the theoretical length based on cytological studies (700-910 cM). The discrepancy between both estimates (expected and theoretical genome lengths) is smaller than that identified in two separate studies on C. gigas: $42-99 \%$ (Hubert \& Hedgecock 2004) and 32-79\% (Li \& Guo 2004).

The ratios of longest to shortest linkage groups are 10.7:1 and 4.3:1 in the female and male maps respectively. These ratios are greater than the cytological ratio (length of chromosome 1 to length of chromosome 14) observed in several karyological studies in M. edulis: 2:1 (Thiriot-Quiévreux 1984); 1.741.86:1 (Insua et al. 1994). This suggests that gaps remain to be filled and that more markers should be added for a better coverage of the genome. However, Hubert \& Hedgecock (2004) reported slightly higher ratios in C. gigas, 7.6:1 in the female and 13.7:1 in the male, compared to the 2:1 cytological ratio (ThiriotQuiévreux 1984). Therefore, the discrepancy observed between these two ratios is similar in M. edulis and C. gigas.

Genome coverage estimated for both maps is relatively good, at $76.7 \%$ and $75.9 \%$ for framework female and male maps respectively. Genome coverage increased to around $86 \%$ for both maps when associated markers (linked but not mapped) were taken into account. These estimates are similar to the one established in C. gigas: 70-79\% (microsatellite markers: Hubert \& Hedgecock 2004) or 81-92\% (AFLPS: Li \& Guo 2004); and in C. virginica: 70-84\% (AFLPs: Yu \& Guo 2003). Also, only 3\% of markers were unlinked to any other marker in both maps, another indicator that framework maps established in $M$. edulis cover a good proportion of the genome.

Our study reported a similarity of map lengths between sexes, in the range 800-870 cM, obtained with two different software (MapMaker 3.0 and JoinMap 4.0). The linear relationship between linkage distance and recombination rate implies that recombination rates in males and females could be similar in M. edulis. Similar recombination rates were reported between males and females in $P$. japonicus (Li et al. 2003). However, several studies reported large sex-specific differences in recombination rates, generally towards higher recombination rates in females in rainbow trout (Sakamoto et al. 2000), in C. virginica (Yu \& Guo 2003 ) and in P. monodon (Wilson et al. 2002). Most of these studies showed congruence between sex-specific recombination rates and genetic distances, with a longer genetic distance reported in the sex exhibiting higher recombination rates. Nevertheless, caution must be taken in the inference of sex-specific recombination frequency from genetic distance because some studies reported sex-discrepancy between genetic map lengths due to the number of informative markers (Agresti et al. 2000). However, in our study, the number of markers mapped in the female (121) and male (116) maps was similar so it is likely that recombination frequencies between sexes are similar in $M$. edulis. This could be confirmed by pairwise comparisons of average spacing between markers common to male and female maps, particularly after the addition of codominant markers.

Clustering of AFLPs is a common feature of AFLP-based genetic maps and has been observed in several species, e.g. in maize (Castiglioni et al. 1999), rainbow trout (Young et al. 1998), tilapia (Agresti et al. 2000) or channel catfish (Liu et al. 2003). Clustering of AFLPs could result from the non-random distribution of enzymatic restriction sites across the genome, and therefore indirectly from the choice of enzymes of restriction used. In this study, EcoRI and Msel were used for digesting the DNA. EcoRI and Msel restriction sites are relatively AT-rich, and so could reflect the variation in GC content among 
chromosomal regions (Yu \& Guo 2003). Contrary to studies on oysters, clustering of AFLPs seems to occur more towards centromeric regions than telomeric ones in the blue mussel (G1M, G3M or G10M). As chromosomes of $M$. edulis are mostly metacentric or submetacentric (Thiriot-Quiévreux 1984; Insua et al. 1994), this clustering could correspond to centromeric suppression of recombination, associated with heterochromatin (Tanksley et al. 1992).

The large intervals (>20 cM), observed in both maps, could be due to the medium-density of the maps obtained, and it is expected that adding markers should reduce those gaps. Alternatively, they could correspond to hot-spot regions of recombination in the genome.

The consensus map presented in this study, even though incomplete, shows the feasibility of an AFLP-based mapping strategy in an undomesticated marine species. However, to increase the accuracy of the consensus map, more 3:1 markers should be scored, to base the consensus map on more than three markers per group, and markers should be chosen to be more evenly spaced throughout each linkage group. More importantly, adding codominant markers such as microsatellites, SNPs or ESTs (type I markers), serving as anchor loci between the two parental maps, will increase the accuracy of the consensus map as well as its portability in the context of QTL mapping. Efforts were made in our study to use the published microsatellite loci (Presa et al. 2002) but we could not achieve reliable results. The combination of dominant (AFLPs or RAPDs) and codominant (microsatellites) markers proved to be very useful for the construction of a consensus map in rainbow trout (Nichols et al. 2003), tilapia (Kocher et al. 1998), zebrafish (Johnson et al. 1996) and common carp (Sun \& Liang 2004). To facilitate the mapping of type I markers, the DNA from the mapping family can be made available to the research community.

Future work could include the production of additional mapping families involving crosses between M. edulis and M. galloprovincialis that will be useful for mapping the numerous type I markers already developed in M. galloprovincialis (Venier et al. 2003; Venier et al. 2006). Such families could be used to investigate QTLs affecting production and life history traits that differ between the two taxa.

\section{Acknowledgements}

This work was funded by INTERREG IIIB (Atlantic Aquaculture Arc Group, AAAG). We particularly thank Dr. Christophe Plomion and Dr. Catherine Bodenes (INRA, France) for their useful advice on MapMaker and JoinMap software. Thanks are due to Dr. Richard Braithwaite and Serge Heurtebise for their help during the production of families of mussels. 


\section{References}

Agresti J.J., Seki S., Cnaani A., Poompuang S., Hallerman E.M., Umiel N., Hulata G., Gall G.A.E. \& May B. (2000) Breeding new strains of tilapia: development of an artificial center of origin and linkage map based on AFLP and microsatellite loci. Aquaculture 185, 43-56.

Beaumont A.R., Beveridge C.M., Barnet E.A., Budd M.D. \& Smyth-Chamosa M. (1988) Genetics studies of laboratory reared Mytilus edulis. I. Genotype specific selection in relation to salinity. Heredity 61 , 389-400.

Beaumont A.R. (1994) Linkage studies in Mytilus edulis, the mussel. Heredity 72, 557-562.

Bierne N., Launey S., Naciri-Graven Y. \& Bonhomme F. (1998) Early effect of inbreeding as revealed by microsatellite analyses on Ostrea edulis larvae. Genetics 148, 1893-1906.

Castiglioni P., Ajmone-Marsan P., Van Wijk R. \& Motto M. (1999) AFLP markers in a molecular linkage map of maize: codominant scoring and linkage group distribution. Theoretical and Applied Genetics 99, 425-431.

Chakravarti A., Lasher L.K. \& Reefer J.E. (1991) A maximum likelihood method for estimating genome length using genetic linkage data. Genetics 128, 175-182.

Gosling E.M. (1992) The Mussel Mytilus: ecology, physiology, genetics, and culture, Amsterdam, Elsevier.

Grattapaglia D. \& Sederoff R. (1994) Genetic linkage maps of Eucalyptus grandis and Eucalyptus urophylla using a pseudo-testcross: mapping strategy and RAPD markers. Genetics 137, 1121-1137.

Hubert S. \& Hedgecock D. (2004) Linkage maps of microsatellite DNA markers for the Pacific oyster Crassostrea gigas. Genetics 168, 351-362.

Insua A., Labat J.P. \& Thiriot-Quievreux C. (1994) Comparative analysis of karyotypes and nucleolar organizer regions in different populations of Mytilus trossulus, Mytilus edulis and Mytilus galloprovincialis. Journal of Molluscan Studies 60, 359-360.

Johnson S.L., Gates M.A., Johnson M., Talbot W.S., Horne S., Baik K., Rude S., Wong J.R. \& Postlethwait J.H. (1996) Centromere-linkage analysis and consolidation of the zebrafish genetic map. Genetics 142, 1277-1288.

Jones C.J., Edwards K.J., Castaglione S., Winfield M.O., Sala F., Van Der Wiel C., Vosman B., Matthes M., Daly A. \& Brettschneider R. (1998) Reproducibility testing of AFLPs by a network of European laboratories. In: Molecular tools for screening biodiversity (ed. by A. Karp, P.G. Isaac \& D.S. Ingram), pp. 183-192. Chapman and Hall, London.

Kocher T.D., Lee W.J., Sobolewska H., Penman D. \& Mcandrew B. (1998) A genetic linkage map of a cichlid fish, the tilapia (Oreochromis niloticus). Genetics 148, 1225-1232.

Kosambi D.D. (1944) The estimation of map distances from recombination values. Annals of Eugenics 12, 172-175.

Lander E.S., Green P., Abrahamson J., Barlow A., Daly M.J., Lincoln S.E. \& Newburg L. (1987) MAPMAKER: an interactive computer package for constructing primary genetic linkage maps of experimental and natural populations. Genomics 1, 174-181.

Launey S. \& Hedgecock D. (2001) High genetic load in the Pacific oyster Crassostrea gigas. Genetics $159,255-265$.

Li L. \& Guo X. (2004) AFLP-based genetic linkage maps of the pacific oyster Crassostrea gigas Thunberg. Marine Biotechnology 6, 26-36.

Li L., Xiang J., Liu X., Zhang Y., Dong B. \& Zhang X. (2005) Construction of AFLP-based genetic linkage map for Zhikong scallop, Chlamys farreri Jones et Preston and mapping of sex-linked markers. Aquaculture 245, 63-73.

Li Y., Byrne K., Miggiano E., Whan V., Moore S., Keys S., Crocos P., Preston N. \& Lehnert S. (2003) Genetic mapping of the kuruma prawn Penaeus japonicus using AFLP markers. Aquaculture 219, 143-156.

Li Z., Li J., Wang Q., He Y. \& Liu P. (2006) AFLP-based genetic linkage map of marine shrimp Penaeus (Fenneropenaeus) chinensis. Aquaculture 261, 463-472.

Lincoln S.E. \& Lander E.S. (1992) Systematic detection of errors in genetic linkage data. Genomics 14, 604-610.

Liu Z., Karsi A., Li P., Cao D. \& Dunham R. (2003) An AFLP-based genetic linkage map of channel catfish (Ictalurus punctatus) constructed by using an interspecific hybrid resource family. Genetics 165, 687694. 
Liu Z.J. \& Cordes J.F. (2004) DNA marker technologies and their applications in aquaculture genetics. Aquaculture 238, 1-37.

Mallet A.L., Freeman K.R. \& Dickie L.M. (1986) The genetics of production characters in the blue mussel Mytilus edulis. I. A preliminary analysis. Aquaculture 57, 133-140.

Mcgoldrick D.J. \& Hedgecock D. (1997) Fixation, segregation and linkage of allozyme loci in inbred families of the Pacific oyster Crassostrea gigas (Thunberg): implications for the causes of inbreeding depression. Genetics 146, 321-334.

Moen T., Hoyheim B., Munck H. \& Gomez-Raya L. (2004) A linkage map of Atlantic salmon (Salmo salar) reveals an uncommonly large difference in recombination rate between the sexes. Animal Genetics 35, 81-92.

Nichols K.M., Young W.P., Danzmann R.G., Robison B.D., Rexroad C., Noakes M., Phillips R.B., Bentzen P., Spies I., Knudsen K., Allendorf F.W., Cunningham B.M., Brunelli J., Zhang H., Ristow S., Drew R., Brown K.H., Wheeler P.A. \& Thorgaard G.H. (2003) A consolidated linkage map for rainbow trout (Oncorhynchus mykiss). Animal Genetics 34, 102-115.

Presa P., Pérez M. \& Diz A.P. (2002) Polymorphic microsatellite markers for blue mussels (Mytilus spp.). Conservation genetics 3, 441-443.

Sakamoto T., Danzmann R.G., Gharbi K., Howard P., Ozaki A., Khoo S.K., Woram R.A., Okamoto N., Ferguson M.M., Holm L.E., Guyomard R. \& Hoyheim B. (2000) A microsatellite linkage map of rainbow trout (Oncorhynchus mykiss) characterized by large sex-specific differences in recombination rates. Genetics 155, 1331-1345.

Stromgren T. \& Nielsen M.V. (1989) Heritability of growth in larvae and juveniles of Mytilus edulis. Aquaculture 80, 1-6.

Sun X. \& Liang L. (2004) A genetic linkage map of common carp (Cyprinus carpio L.) and mapping of a locus associated with cold tolerance. Aquaculture 238, 165-172.

Tanksley S.D., Ganal M.W., Prince J.P., De-Vicente M.C., Bonierbale M.W., Broun P., Fulton T.M., Giovannoni J.J., Grandillo S., Martin G.B., Messeguer R., Miller J.C., Miller L., Paterson A.H., Pineda O., Roder M.S., Wing R.A., Wu W. \& Young N.D. (1992) High density molecular linkage maps of the tomato and potato genomes. Genetics 132, 1141-1160.

Thiriot-Quiévreux C. (1984) Chromosome analysis of three species of Mytilus (Bivalvia: Mytilidae). Marine Biology Letter 5, 265-273.

Utting S.D. \& Spencer B.E. (1991) The hatchery culture of bivalve mollusc larvae and juveniles. Laboratory leaflet number 68. Lowestoft, Ministry of agriculture, fisheries and food directorate of fisheries research.

Van Ooijen J.W. (2006) JoinMap 4, Software for the calculation of genetic linkage maps in experimental populations. Wageningen, Netherlands, Kyazma, B. V.

Venier P., Pallavicini A., De Nardi B. \& Lanfranchi G. (2003) Towards a catalogue of genes transcribed in multiple tissues of Mytilus galloprovincialis. Gene 314, 29-40.

Venier P., De Pitta C., Pallavicini A., Marsano F., Varotto L., Romualdi C., Dondero F., Viarengo A. \& Lanfranchi G. (2006) Development of mussel mRNA profiling: Can gene expression trends reveal coastal water pollution? Mutation Research 602, 121-134.

Voorrips R.E. (2002) MapChart: software for the graphical presentation of linkage maps and QTLs. The journal of heredity $93,77-78$.

Vos P., Hogers R., Bleeker M., Reijans M., Van De Lee T., Hornes M., Frijters A., Pot J., Peleman J., Kuiper M. \& Zabeau M. (1995) AFLP: a new technique for DNA fingerprinting. Nucleic Acids Research 23, 4407-4414.

Wang L., Song L., Chang Y., Xu W., Ni D. \& Guo X. (2005) A preliminary genetic map of Zhikong scallop (Chlamys farreri Jones et Preston 1904). Aquaculture Research 36, 643-653.

Wang S., Bao Z., Pan J., Zhang L., Yao B., Zhan A., Bi K. \& Zhang Q. (2004) AFLP linkage map of an intraspecific cross in Chlamys farreri. Journal of Shellfish Research 23, 491-499.

Wilding C.S., Butlin R.K. \& Grahame J. (2001) Differential gene exchange between parapatric morphs of Littorina saxatilis detected using AFLP markers. Journal of Evolutionary Biology 14, 611-619.

Wilson K., Li Y., Whan V., Lehnert S., Byrne K., Moore S., Pongsomboon S., Tassanakajon A., Rosenberg G., Ballment E., Fayazi Z., Swan J., Kenway M. \& Benzie J. (2002) Genetic mapping of the black tiger shrimp Penaeus monodon with amplified fragment length polymorphism. Aquaculture 204, 297-309. 
Young W.P., Wheeler P.A., Coryell V.H., Keim P. \& Thorgaard G.H. (1998) A detailed linkage map of rainbow trout produced using doubled haploids. Genetics 148, 839-850.

Yu Z. \& Guo X. (2003) Genetic linkage map of the eastern oyster Crassostrea virginica Gmelin. Biological Bulletin 204, 327-338.

Yu Z. \& Guo X. (2006) Identification and mapping of disease-resistance QTLs in the eastern oyster, Crassostrea virginica Gmelin. Aquaculture 254, 160-170. 
Table 1 Length, number of markers (framework and associated), average spacing, largest interval of linkage groups of the female and male maps established with MapMaker 3.0.

\begin{tabular}{|c|c|c|c|c|c|}
\hline $\begin{array}{l}\text { Linkage } \\
\text { group }\end{array}$ & $\begin{array}{l}\text { Length } \\
\text { (cM) }\end{array}$ & $\begin{array}{l}\text { No. of framework } \\
\text { markers }\end{array}$ & $\begin{array}{c}\text { No. of associated } \\
\text { markers }\end{array}$ & $\begin{array}{c}\text { Average } \\
\text { spacing (cM) }\end{array}$ & $\begin{array}{l}\text { Largest interval } \\
\text { (cM) }\end{array}$ \\
\hline \multicolumn{6}{|l|}{ Female: } \\
\hline G1F & 101.5 & 15 & 23 & 7.25 & 27.8 \\
\hline G2F & 101.3 & 11 & 12 & 10.13 & 32.9 \\
\hline G3F & 83.3 & 10 & 13 & 9.25 & 21.9 \\
\hline G4F & 76.0 & 10 & 5 & 8.40 & 28.3 \\
\hline G5F & 75.2 & 10 & 8 & 8.35 & 31.0 \\
\hline G6F & 69.9 & 7 & 3 & 11.65 & 26.7 \\
\hline G7F & 66.7 & 9 & 5 & 8.34 & 28.9 \\
\hline G8F & 65.8 & 8 & 4 & 9.40 & 22.3 \\
\hline G9F & 61.6 & 9 & 11 & 7.7 & 22.5 \\
\hline G10F & 61.3 & 16 & 11 & 4.09 & 14.3 \\
\hline G11F & 60.2 & 10 & 11 & 6.69 & 25.4 \\
\hline G12F & 19.5 & 2 & 0 & 19.5 & 19.5 \\
\hline G13F & 11.0 & 2 & 5 & 11.0 & 11.0 \\
\hline G14F & 9.5 & 2 & 4 & 9.5 & 9.5 \\
\hline Total & 862.8 & 121 & 115 & 8.06 & 32.9 \\
\hline \multicolumn{6}{|l|}{ Male: } \\
\hline G1M & 86.5 & 13 & 9 & 7.21 & 37.6 \\
\hline G2M & 84.9 & 10 & 10 & 9.43 & 22.1 \\
\hline G3M & 79.5 & 7 & 14 & 13.25 & 30.8 \\
\hline G4M & 77.8 & 8 & 3 & 11.11 & 23.7 \\
\hline G5M & 74.9 & 10 & 5 & 8.32 & 35.2 \\
\hline G6M & 61.6 & 5 & 10 & 15.4 & 23.9 \\
\hline G7M & 61.2 & 6 & 5 & 12.24 & 24.1 \\
\hline G8M & 60.2 & 20 & 7 & 3.17 & 16.9 \\
\hline G9M & 57.6 & 7 & 5 & 9.6 & 12.9 \\
\hline G10M & 57.0 & 8 & 5 & 8.14 & 25.2 \\
\hline G11M & 53.0 & 5 & 5 & 13.25 & 20.4 \\
\hline G12M & 26.4 & 5 & 1 & 6.6 & 16.0 \\
\hline G13M & 24.3 & 9 & 7 & 3.08 & 8.2 \\
\hline G14M & 20.3 & 3 & 2 & 10.15 & 11.5 \\
\hline Total & 825.2 & 116 & 88 & 8.09 & 37.6 \\
\hline
\end{tabular}


Supplemental Table S1 Primer pairs used for scoring AFLPs, with their abbreviations.

\begin{tabular}{cccc}
\hline & $\begin{array}{c}\text { ECO+CAG } \\
\text { FAM }\end{array}$ & $\begin{array}{c}\text { ECo+ACG } \\
\text { HEX }\end{array}$ & $\begin{array}{c}\text { Eco+ACT } \\
\text { NED }\end{array}$ \\
\hline Mse+CGA & A1 & B1 & E1 \\
Mse+CAA & A2 & B2 & E2 \\
Mse+CTG & A3 & B3 & E3 \\
Mse+CAT & A4 & B4 & E4 \\
Mse+CTT & A5 & B5 & E5 \\
Mse+ATC & A6 & B6 & E6 \\
Mse+AGT & A7 & B7 & E7 \\
Mse+CTC & A8 & B8 & E8 \\
Mse+CTA & A9 & B9 & E9 \\
Mse+CAC & A10 & B10 & E10 \\
Mse+CAG & A11 & B11 & E11 \\
Mse+CCT & A12 & B12 & E12 \\
\hline
\end{tabular}


Supplemental Table S2 Associated markers of the female map (linked but not mapped).

\begin{tabular}{|c|c|c|}
\hline Group name & Framework marker & Associated markers \\
\hline \multirow[t]{4}{*}{ G1F } & A12f227 & A7f177, A10f102, B4f63r, B11f166, A1f162r, A11f41r \\
\hline & E12f138 & E4f99, B5f119, B10f119, B12f119, E10f229r, B9f119 \\
\hline & E4f57 & $E 6 f 177 r, E 8 f 294 r$ \\
\hline & A7f99r & $\begin{array}{l}\text { E3f84r, B6f166r, B6f82, A3f176, A1f83, A1f106, B9f64, B9f120, } \\
\text { A10f171r }\end{array}$ \\
\hline \multirow[t]{4}{*}{ G2F } & E5f88r & $B 5 f 88 r$ \\
\hline & E10f44r & A3f133r \\
\hline & $B 8 f 97 r$ & E11f225 \\
\hline & A10f39 & $\begin{array}{l}\text { A3f153, B1f191, A9f287, A4f341r, E12f51r, B11f170r, B5f57r, } \\
\text { E3f94, B9f179 }\end{array}$ \\
\hline \multirow[t]{4}{*}{ G3F } & B4f303 & $A 8 f 201 r, A 9 f 164 r$ \\
\hline & E1f211 & $B 3 f 48 r, E 7 f 140$ \\
\hline & E11f130r & A7f40r, E7f100 \\
\hline & A9f195r & B3f129, B3f136r, A1f249r, B11f248, A3f291, B3f137, B1f47r \\
\hline \multirow[t]{2}{*}{ G4F } & $B 1 f 178$ & A10f162r \\
\hline & A1f41 & E10f102, E10f133, E8f258r, A10f237 \\
\hline \multirow[t]{2}{*}{ G5F } & E9f115r & A1f242, E11f238, E1f152r \\
\hline & B1f55 & A10f54, A10f88, A11f102, A6f132r, B12f150r \\
\hline \multirow[t]{2}{*}{ G6F } & A4f109r & E3f193r \\
\hline & E10f171 & A1f126, A5f110 \\
\hline \multirow[t]{2}{*}{ G7F } & E12f191r & A1f173, A1f174, B11f148r \\
\hline & A8f76r & E12f163r, A7f180 \\
\hline \multirow[t]{3}{*}{ G8F } & A3f123 & $B 6 f 230, B 11 f 43$ \\
\hline & A10f328 & $E 3 f 279$ \\
\hline & $E 12 f 241$ & A11f323 \\
\hline \multirow[t]{4}{*}{ G9F } & A1f191 & A7f343, A7f348r, A6f196, E7f63r, E6f173 \\
\hline & E8f289 & B5f311, E1f167 \\
\hline & $B 5 f 179 r$ & A4f168 \\
\hline & $B 7 f 217 r$ & E8f66r, B9f152r, A7f238 \\
\hline \multirow[t]{4}{*}{ G10F } & A5f97 & $B 3 f 303, E 1 f 72 r$ \\
\hline & $B 1 f 133$ & E10f83, A7f252r, B10f372r \\
\hline & E3f183r & A4f205, A11f197, E12f96 \\
\hline & A9f41 & E11f160, A11f114r, B11f91 \\
\hline \multirow[t]{3}{*}{ G11F } & A11f110 & $E 4 f 121 r$ \\
\hline & B4f65 & A7f66, B8f199r \\
\hline & A7f134 & $\begin{array}{l}\text { B1f154, E3f105, A4f269, E11f136, B12f135, E1f278r, E9f181r, } \\
\text { B9f52 }\end{array}$ \\
\hline \multirow[t]{2}{*}{ G13F } & A7f141 & A9f73, B12f271, A11f83r, E11f70 \\
\hline & A8f93 & A9f183 \\
\hline \multirow[t]{2}{*}{ G14F } & B1f259 & E1f303r \\
\hline & A12f288r & A8f98, B12f330, B11f263r \\
\hline
\end{tabular}


Supplemental Table S3 Associated markers of the male map (linked but not mapped).

\begin{tabular}{|c|c|c|}
\hline Group name & Framework marker & Associated markers \\
\hline \multirow[t]{5}{*}{ G1M } & A9f76 & A1f205, E1f56r, A8f193r \\
\hline & A4f146 & $B 6 f 66$ \\
\hline & A6f165r & A1f42 \\
\hline & A10f107 & B3f122, A7f100r, A9f161r \\
\hline & $B 12 f 279 r$ & E11f148 \\
\hline \multirow[t]{3}{*}{ G2M } & B4f132 & A1f264, B3f269, A4f138, A4f143, B6f266, E12f97, A12f77r \\
\hline & E11f193r & E10f128 \\
\hline & A7f318 & A7f346r \\
\hline \multirow[t]{3}{*}{ G3M } & A5f116r & E1f76 \\
\hline & A10f209r & B4f129, A5f124, A10f143, A12f50, B10f228r, B11f64r \\
\hline & B10f53r & A5f169, B9f74, B12f168, E1f95r, B8f113r, B8f128r, B8f204r \\
\hline G4M & E7f172 & A4f183, E12f155, E4f42r \\
\hline \multirow[t]{3}{*}{ G5M } & A9f334r & $B 4 f 125, E 4 f 153 r$ \\
\hline & $B 12 f 138 r$ & E6f106 \\
\hline & $B 6 f 161 r$ & $B 11 f 86, B 9 f 108 r$ \\
\hline \multirow[t]{2}{*}{ G6M } & E1f235 & $\begin{array}{l}\text { A8f167, B11f151, A7f75r, B6f105, B10f314, A3f327r, E7f84, } \\
\text { B4f213r, E9f171r }\end{array}$ \\
\hline & E5f121r & E7f150r \\
\hline \multirow[t]{2}{*}{ G7M } & $E 4 f 273 r$ & A1f273, A4f120, A10f97, A10f41r \\
\hline & A10f106r & A4f43 \\
\hline \multirow[t]{4}{*}{ G8M } & $B 4 f 262$ & E9f112r \\
\hline & E8f77 & $B 12 f 229$ \\
\hline & $B 11 f 355 r$ & A6f167r \\
\hline & $B 11 f 152 r$ & A1f204, A7f241, A10f270r \\
\hline \multirow[t]{3}{*}{ G9M } & $B 6 f 51$ & B10f198r \\
\hline & A11f262r & A3f88, E7f234, E11f96 \\
\hline & B10f188 & A11f280r \\
\hline G10M & A6f87 & A7f55, B7f128, E9f282, A7f340r, B7f106r \\
\hline \multirow[t]{3}{*}{ G11M } & A4f296 & A5f119, E9f105, E11f111 \\
\hline & E12f56 & E10f40r \\
\hline & A6f81r & $B 7 f 126 r$ \\
\hline G12M & E10f94r & A8f134 \\
\hline \multirow[t]{3}{*}{ G13M } & A1f77 & A1f100r, B3f318r \\
\hline & E9f193 & A3f70, A3f109r \\
\hline & E11f104r & B1f107, A3f39r, A5f139r \\
\hline \multirow[t]{2}{*}{ G14M } & B11f67 & E7f94 \\
\hline & E4f156r & A11f325 \\
\hline
\end{tabular}




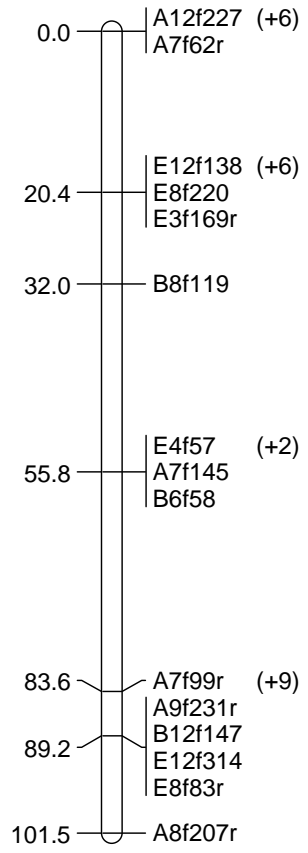

G8F

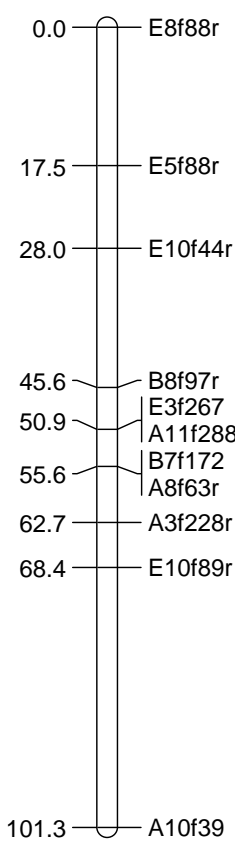

G9F

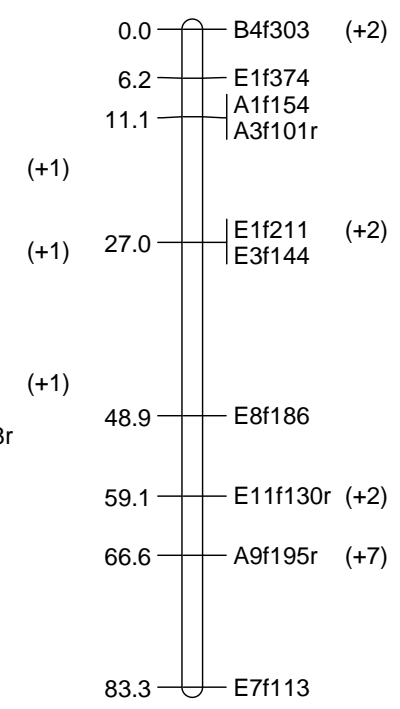

$(+9)$

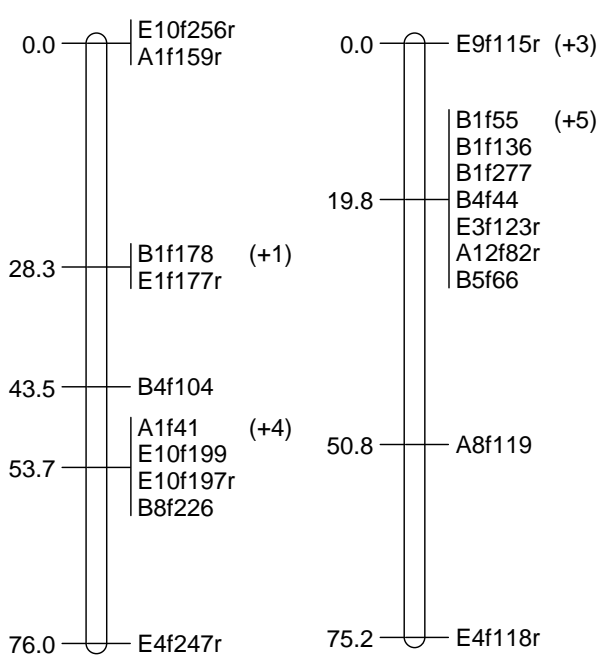

G11F

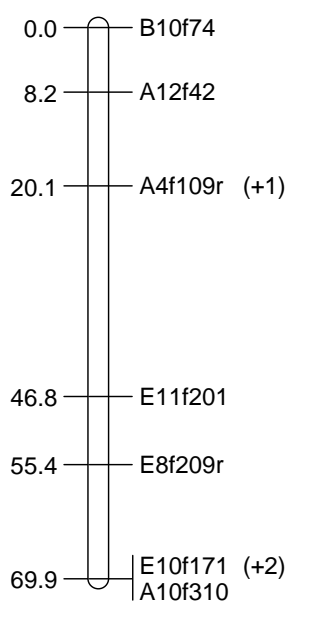

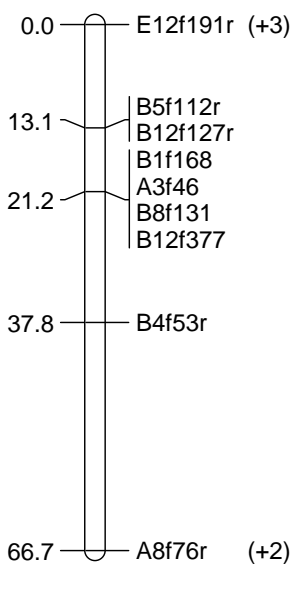

$(+2)$
G10F
G12F
G13F

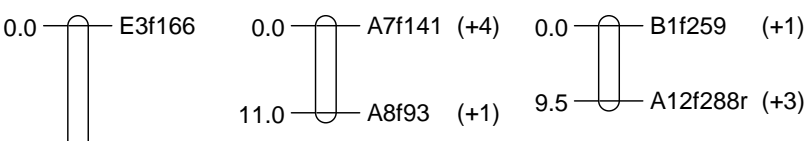

G14F
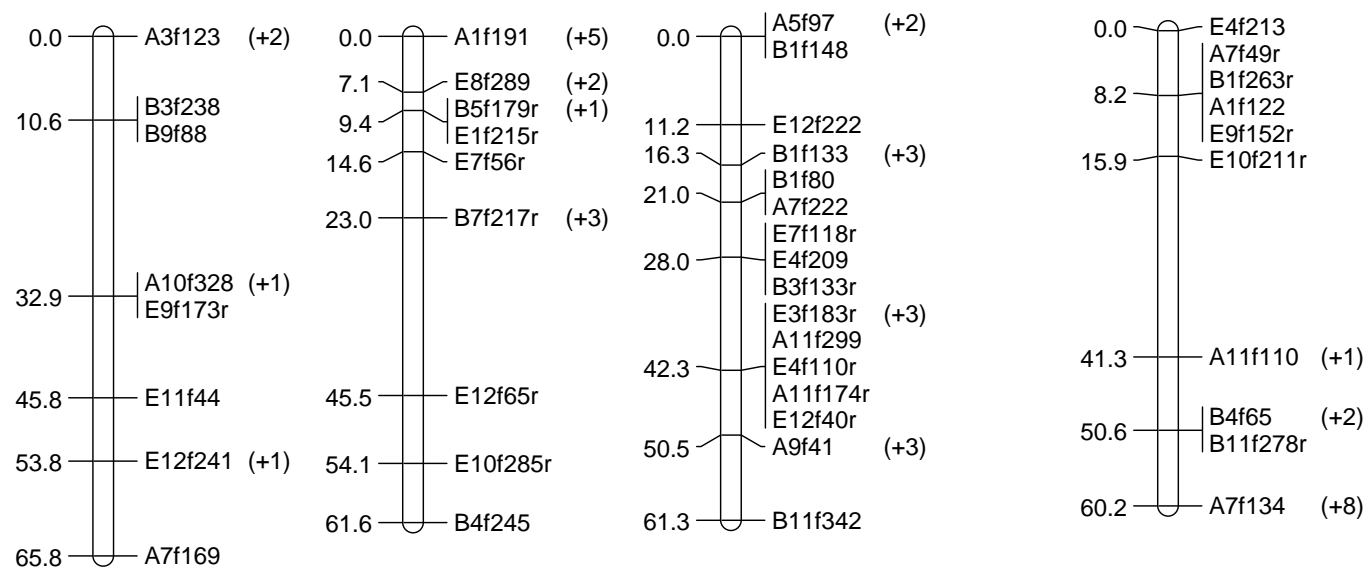

Figure 1. AFLP linkage map of the blue mussel $M$. edulis: Female map obtained with MapMaker 3.0, including 121 framework markers for a total of $863 \mathrm{cM}$. AFLP markers are labelled with the primer pair name followed by the letter " $\mathrm{f}$ " (for fragment) and a 3-digit fragment size in base pairs. Markers are indicated on the right and absolute positions on the left (in Kosambi cM). Numbers in brackets on the right of locus name correspond to number of associated markers (linked but unplaced). 


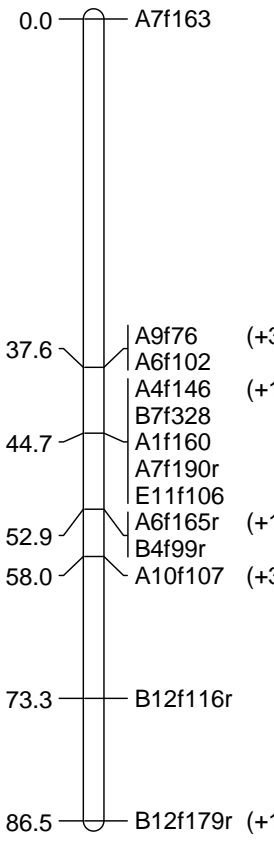

G8M

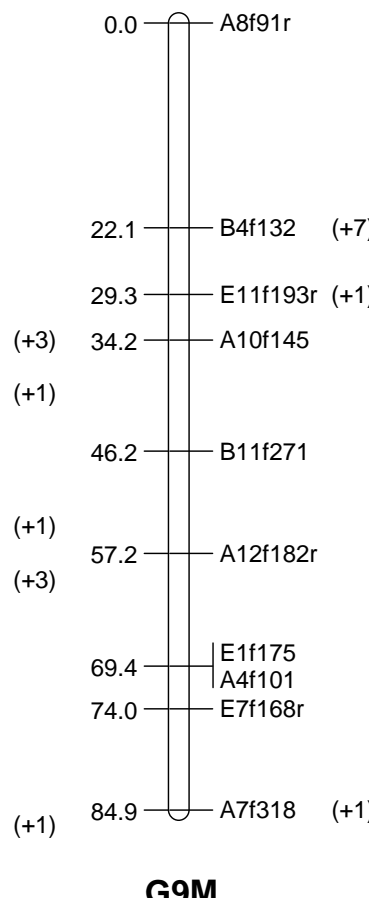

G9M

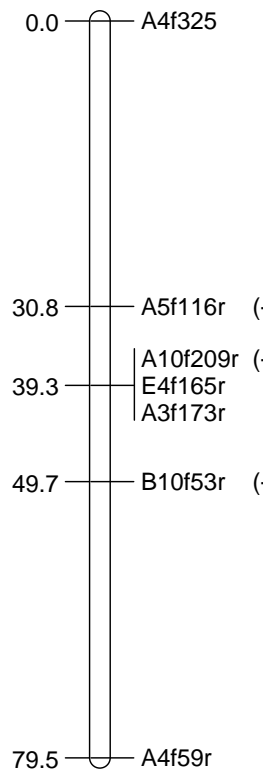

G10M

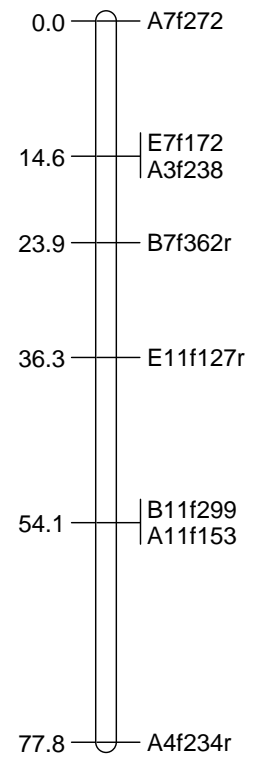

G11M

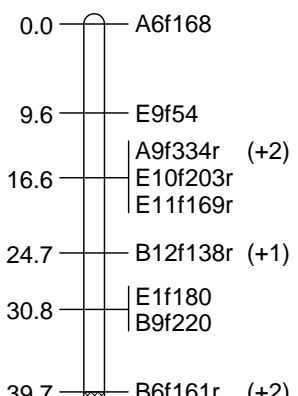

$39.7+\frac{1}{x}$ B6f161r (+2)

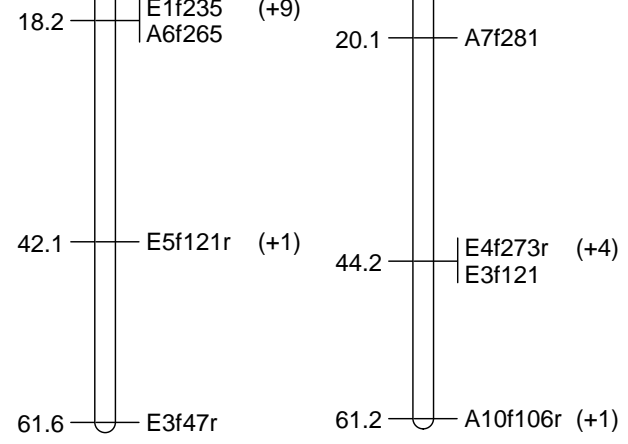

$(+1)$

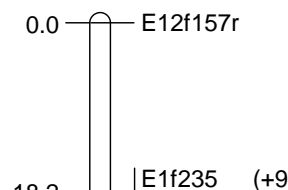

$5 \quad(+9)$

74.9 A6f121r LOD=-2.79

G12M

G13M

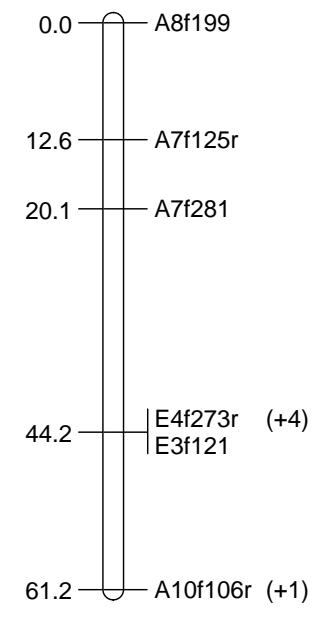

G14M
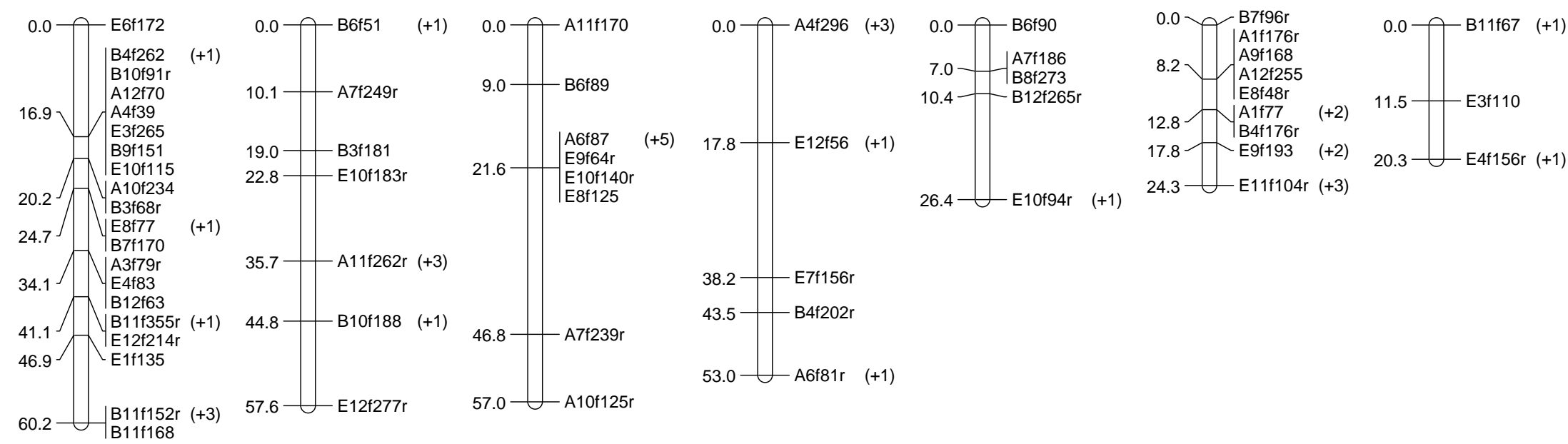

$(+1)$

Figure 2. AFLP linkage map of the blue mussel M. edulis: Male map obtained with MapMaker 3.0, including 116 framework markers for a total of $825 \mathrm{cM}$. AFLP markers are labelled with the primer pair name followed by the letter "f" (for fragment) and a 3-digit fragment size in base pairs. Markers are indicated on the right and absolute positions on the left (in Kosambi cM). Numbers in brackets on the right of locus name correspond to number of associated markers (linked but unplaced). 
Figure 3. Consensus map established in the blue mussel $M$. edulis, in a mapping family including two parents and 86 F1 progeny using JoinMap 4.0 software. The consensus map is based on the finding of nine homologous pairs of linkage groups. Homologous markers are displayed in bold and underlined, ending with an asterisk (*). AFLP markers are labelled with the primer pair name followed by the letter "f" (for fragment) and a 3-digit fragment size in base pairs. Markers are indicated on the right and absolute positions on the left (in Kosambi cM).

G1F_G5M_comb

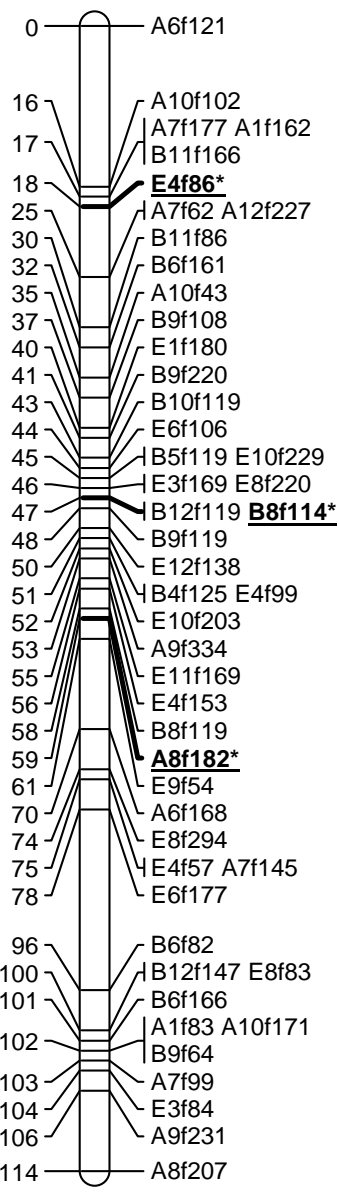

G6F_G9M_comb G2F_G8M_comb

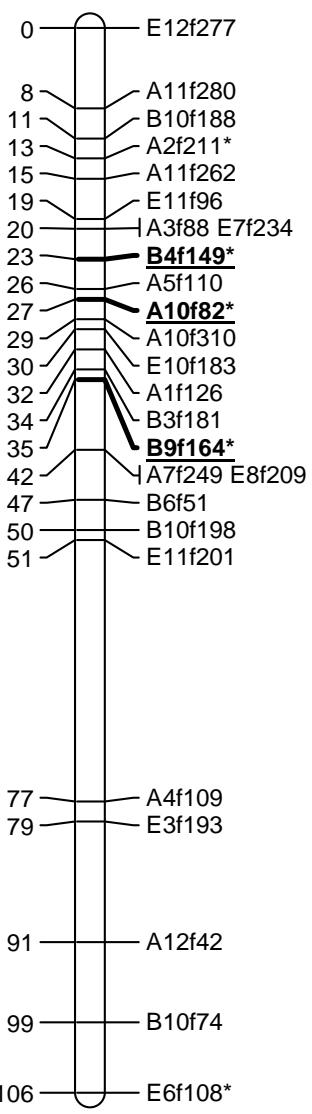

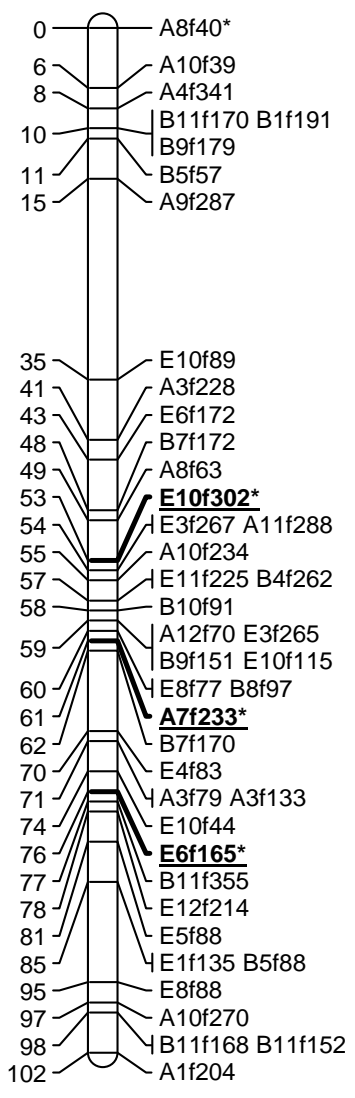

G9F_G2M_comb

G4F_G4M_comb
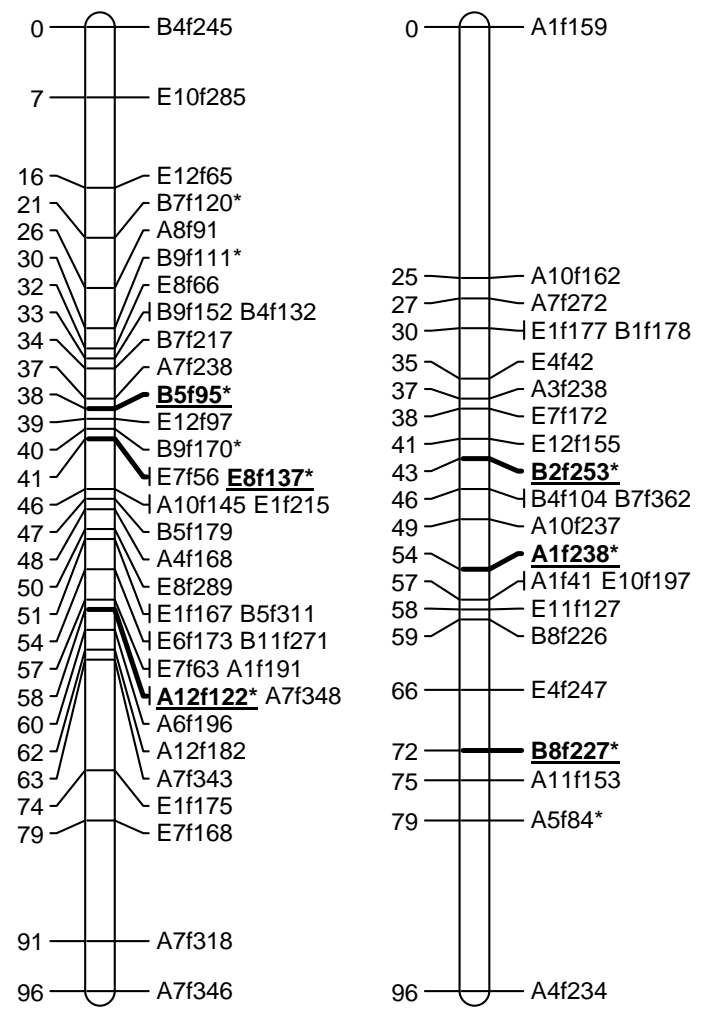

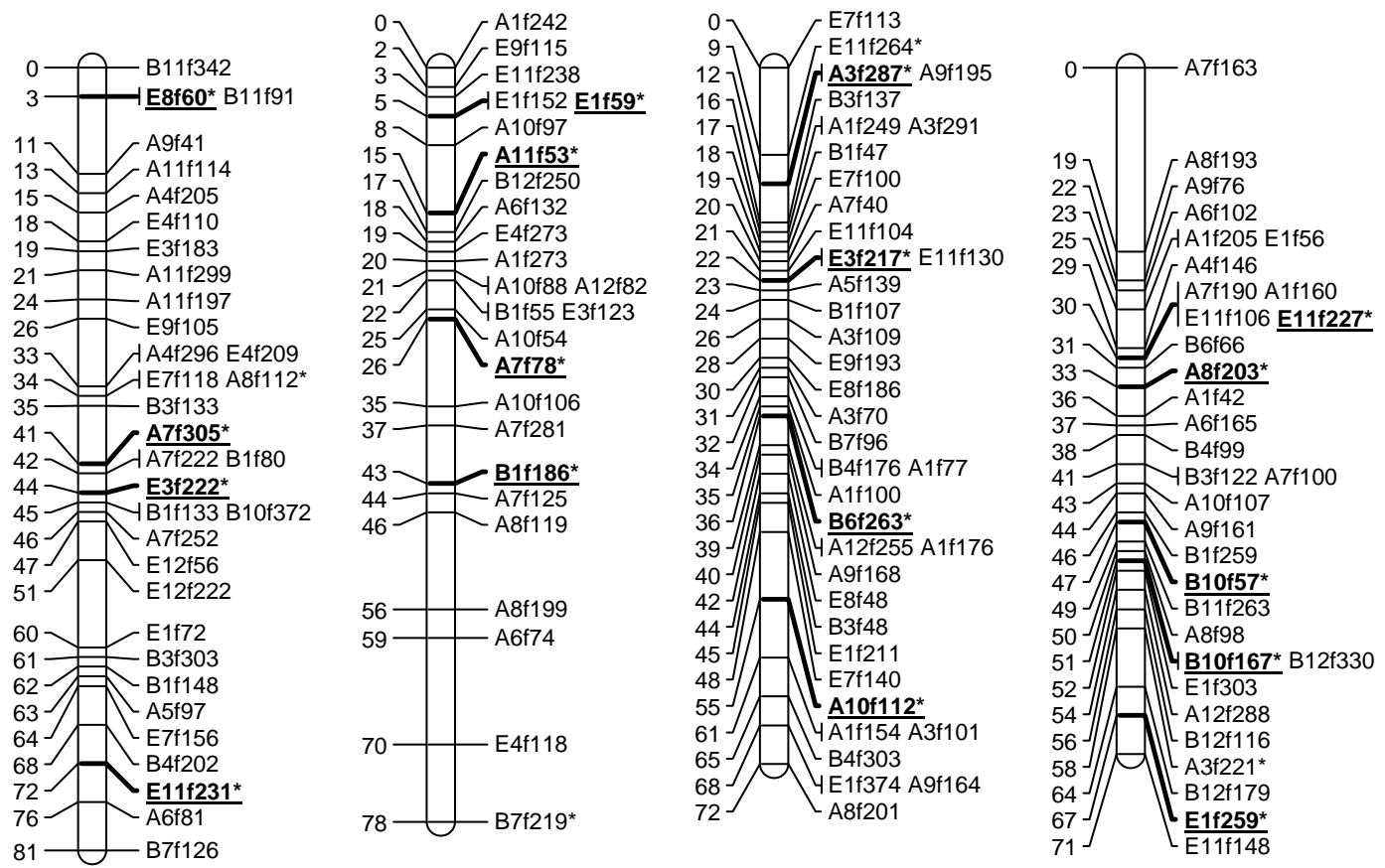

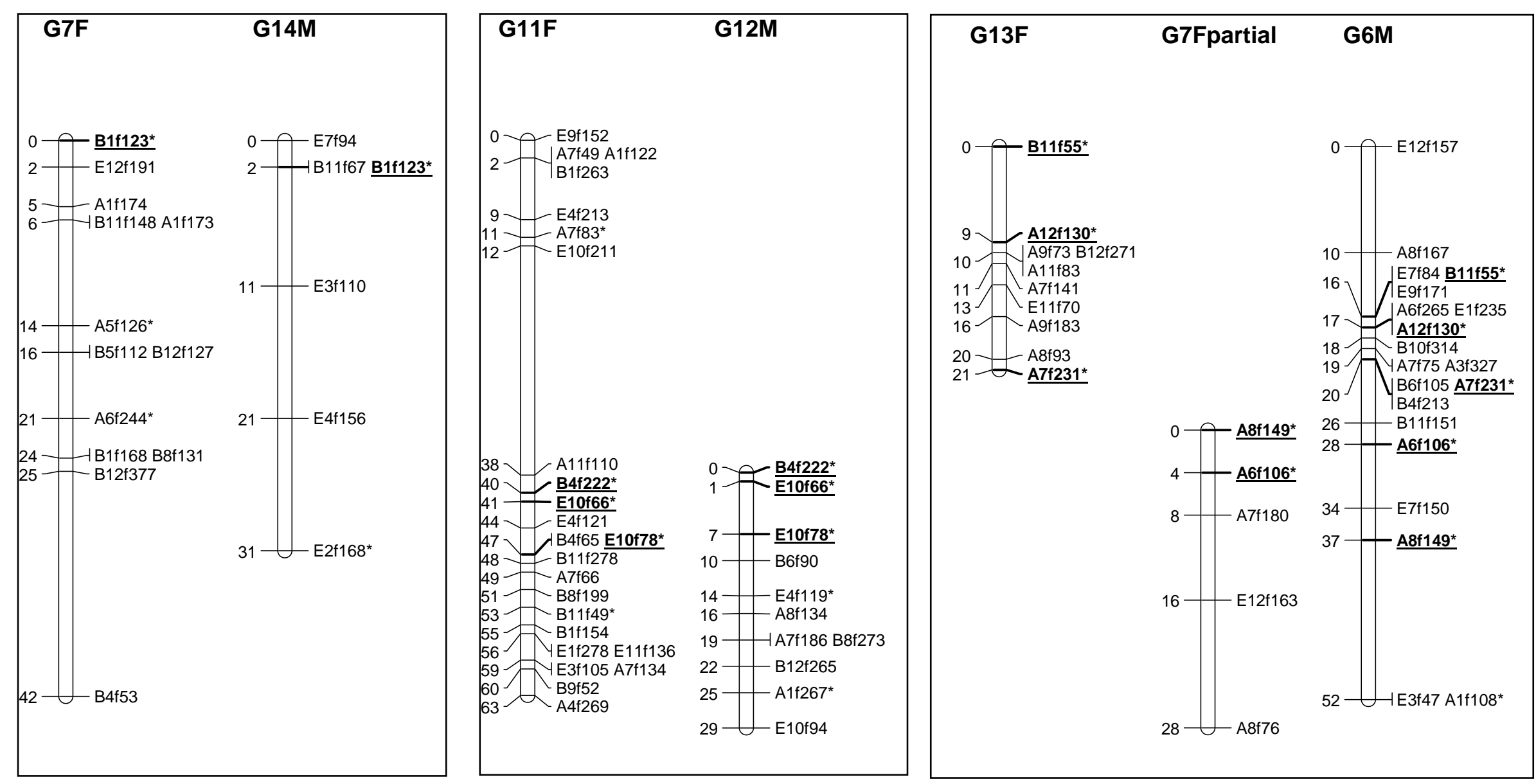

Figure 4. Probable homologies between female and male groups assessed by the mapping of 3:1 markers in M. edulis using JoinMap 4.0 software. Three pairs of likely homologous are represented for which no consensus map could be established. Pairs of homologous markers are displayed in bold and underlined, ending with an asterisk $\left(^{*}\right)$. AFLP markers are labeled with the primer pair name followed by the letter "f” (for fragment) and a 3-digit fragment size in base pairs. Markers are indicated on the right and absolute positions on the left (in Kosambi cM). 